\title{
EVALUATION OF DEXMEDETOMIDINE ON HEMODYNAMIC STRESS RESPONSE DURING LARYNGOSCOPY AND INTUBATION
}

\author{
Abdul Raafeh Jamal, Bilal Yasin, Mohammad Saeed, Rao Ali Shan Khan, Syed Hamid Ali Shah*, Muhammad Zeeshan Akbar \\ Combined Military Hospital/National University of Medical Sciences (NUMS) Rawalpindi Pakistan, *Bahria International Hospital, Islamabad Pakistan
}

\section{ABSTRACT}

Objective: To compare the efficacy of Dexmedetomidine (Precedex) in addressing the mean haemodynamic stress response to laryngoscopy and endotracheal intubation (L\&I).

Study Design: Quasi-experimental study.

Place and Duration of Study: Anesthesiology Department, Combined Military Hospital, Rawalpindi, from Jun 2019 Jun 2020.

Methodology: The patients were divided into two groups. Group A was given Inj. Dexmedetomidine and group B (placebo). Operation theatre assistant randomly assigned the patients to either group A or group B each day. The second person administered the drug or placebo. The third person (researcher) recorded all the parameters mentioned in the proforma.

Results: There were 100 patients with an age range of 18-60 years. The majority of the patients were ASA-I physical status. The main surgical procedure was laparoscopic cholecystectomy. Recording of heart rate and systolic blood pressure during laryngoscopy and intubation, after administration of drug or placebo, showed mean heart rate less than mean basal value in group-A and $22 \%$ above mean basal value in group- $\mathrm{B}$, and it was statistically highly significant $(p$-value $<0.001)$. Whereas mean systolic blood pressure in group-A was $122.42 \pm 14.91$ (less than the mean basal value) as compared to group B, $155.00 \pm$ $18.32 / \min (20 \%$ above mean basal value). This change was also statistically highly significant ( $p$-value $<0.001)$.

Conclusion: It is concluded that dexmedetomidine showed statistically significant stabilizing effects on the expected changes of the hemodynamic stress response.

Keywords: Dexmedetomidine, Hemodynamic changes, Hypertension, Intubation, Laryngoscopy, Tachycardia.

How to Cite This Article: Jamal AR, Yaseen B, Saeed M, Khan RAS, Shah SHA, Akbar MZ. Evaluation of Dexmedetomidine on Hemodynamic Stress Response During Laryngoscopy And Intubation. Pak Armed Forces Med J 2021; 71(6): 2126-2130. Doi: https://doi.org/10.51253/pafmj.v71i6.6584

This is an Open Access article distributed under the terms of the Creative Commons Attribution License (https://creativecommons.org/licenses/by-nc/4.0/), which permits unrestricted use, distribution, and reproduction in any medium provided the original work is properly cited.

\section{INTRODUCTION}

The airway control during general anaesthesia is provided by laryngoscopy and intubation. The mechanical and chemical stimuli are also induced during laryngoscopy and intubation. There are reflex responses of the cardiovascular and respiratory systems caused by mechanical stimuli. ${ }^{1}$ Mostly this response reaches its maximum level within one min and ends in 5$10 \mathrm{~min}$ after intubation. The catecholamine is released by an increase due to chemical stimulus. It leads to hypertension, tachycardia and may lead to arrhythmias. Tachycardia generates a more powerful load on the heart when compared with hypertension as it increases oxygen consumption of the myocardium, decreases diastolic filling and finally reduces coronary blood supply. ${ }^{2}$ Narcotic analgesics, local anaesthetics, beta-blockers, calcium channel blockers, vasodilators and nonpharmaceutical strategies are employed in order to control that response. ${ }^{3}$ Dexmedetomidine is a highly selective alpha-2 adrenoceptor (a2-AR) agonist. It has

Correspondence: Dr Abdul Raafeh Jamal, Deptof Anaesthesiology, Combined Military Hospital, Rawalpindi-Pakistan

Received: 08 Jun 2021; revision received: 23 Aug 2021; accepted: 27 Aug 2021 been introduced to anaesthesia practice relatively recently. It produces sedation, anxiolysis and analgesia without respiratory depression. It involves spinal and supraspinal sites. ${ }^{4}$ It is said that dexmedetomidine significantly reduces the incidence of postoperative cognitive dysfunction (POCD) and improves Mini-Mental State Examination (MMSE) score. ${ }^{5}$ It is equally effective in all age groups and is being used in pediatric age as well as elderly patients. ${ }^{6}$

The rationale of the study is that hemodynamic stress response is initiated during laryngoscopy and intubation, which can be harmful to even a normal person. The use of dexmedetomidine effectively reduces the hemodynamic stress response. In a study by Sulhyan et $a l^{7}$ mean reduction in heart rate (placebo $73.73 \pm 18.23$ \& test group $64.27 \pm 17.34$ ) was found and similarly mean systolic blood pressure was less in the test group (113.47) as compared to placebo (152.60). Therefore, it protects the patient. ${ }^{8}$ A very few analyses of dexmedetomidine are available in the Pakistani population, so this study is being carried out. Furthermore, this study may also be used as a basis for future research on the drug, which may include its use in high-risk cases such as patients at risk of a brain haemorrhage. 


\section{METHODOLOGY}

The study was conducted in Anaesthesiology Department, Combined Military Hospital Rawalpindi, from June 2019 to June 2020, after Ethical Review Board (ERB CMH dt 22-05-2019) approval,. The sample size was calculated using WHO calculator using the mean of the test (64.27) and placebo (73.73) with standard deviation (test group \pm 15.34 and placebo group \pm 18.23), the confidence level of $95 \%$, a margin of error to be $5 \%$, a sample size of 50 was obtained. ${ }^{7}$ Non-probability consecutive sampling was used.

Inclusion Criteria: Adult Patients, 18-60 years of age, American society of anaesthesiologist (ASA) physical status of I and II, scheduled for elective surgery under general anaesthesia requiring endotracheal intubation were included.

Exclusion Criteria: Patients with major systemic disease, patients with anticipated difficult intubation and cases with prolonged duration of laryngoscopy and intubation (>30 seconds) were excluded.

Written informed consent was taken from all patients. The patients were randomly divided into two groups (each of 50 patients), Group A test group, $(\mathrm{n}=50)$ : Inj. Dexmedetomidine $1 \mathrm{mcg} / \mathrm{kg}$ in $100 \mathrm{ml}$ NS. Group B (placebo), $(\mathrm{n}=50)$ : only $100 \mathrm{ml}$ normal saline (NS). A team of three people achieved double-blinding and randomization. The first person (assistant) randomly assigned the patients to either group A or group $B$ by computer-generated random numbers each day and prepared the drug or placebo in $100 \mathrm{ml}$ burette according to the number of patients, selected and to be included in the study for the day. The assistant ensured that the colour and volume of the drug and placebo were similar. The drug and placebo burettes were labelled with the serial number of the cases. The first person kept the record. The second person administered the drug or placebo. The third person (researcher) recorded all the parameters required for the study. Group A was given a $100 \mathrm{ml}$ normal saline infusion containing dexmedetomidine (1 microgram $/ \mathrm{kg}$ ) in 5-10 minutes. While group B was given the placebo, which was containing $100 \mathrm{ml}$ normal saline infusion. The patients were premedicated with Nalbuphine 0.1 $\mathrm{mg} / \mathrm{Kg}$ body weight, metoclopramide $0.25 \mathrm{mg} / \mathrm{Kg}$ and Dexamethasone $0.1 \mathrm{mg} / \mathrm{kg}$, before induction of anaesthesia. The general anaesthesia was induced under standard monitoring. After $3 \mathrm{~min}$ pre-oxygenation, for induction, Propofol was used in a dose of $2 \mathrm{mg} / \mathrm{Kg}$. To facilitate laryngoscopy and endotracheal intubation, Atracurium $0.5 \mathrm{mg} / \mathrm{Kg}$ was used. Later, laryngoscopy using Macintosh blade size 3 or 4 and intubation using an intratracheal tube (size 7-7.5) was performed. The laryngoscopies were performed by an experienced anesthesiologist, to minimize the duration of laryngoscopy. After successful intubation, anaesthesia was maintained with 1-1.5 MAC (inspiratory saturation) of Isoflorane in $\mathrm{O} 2$ and air (50\% mixture). Patients were monitored for hemodynamic changes at a various specific timing. Heart rate and systolic blood pressure, which were recorded just before drug administration to establish a baseline, then 5 and 10 minutes after drug administration. Followed by recording during laryngoscopy and intubation and finally at 1, 3, 5 and 10 minutes after intubation. At the end of the surgery, neuromuscular blockade was reversed with neostigmine 50 microgram $/ \mathrm{kg}$ and glycopyrrolate 10 microgram $/ \mathrm{kg}$ intravenous. After satisfying the extubation criteria, the trachea was extubated and patients were transferred to post anaesthesia care unit. All the data was entered in a specifically designed proforma.

The data obtained in the study for various parameters were presented in tabulated form. Statistical Package for the social sciences (SPSS) version 21 was used for data analysis. Mean and standard deviation was calculated for all the quantitative variables (age, heart rate and blood pressure). Frequency and percentage were calculated for gender, ASA and type of surgery. Comparison among Group A and Group B was done using independent sample t-test and chi-square test were applied. The $p$-value of $\leq 0.05$ was considered statistically significant.

\section{RESULTS}

The 100 selected patients were divided into two groups. Group A test Group, $(n=50)$ and group B (placebo) also had 50 patients. The age range in group A was 18-60 years and in group B, 19-60 years. The patients were also grouped into three different age subgroups as well. In the age group of (18-30 years), there were $19(38 \%)$ in group-A and $17(34 \%)$ patients in group $B$. The second group (31-45 years) comprised $18(36 \%)$ patients in group-A and $19(38 \%)$ in Group B. The last group of (46-60 years) had $13(26 \%)$ and 14 (28\%) patients in both groups. In group A, there were $26(52 \%)$ male and $24(48 \%)$ female patients. Whereas in group B, $29(58 \%)$ male and 21 (42\%) female patients. In this study, the Dexmedetomidine group (group-A) had $37(74 \%)$ patients in ASA-I status and the rest $13(26 \%)$ in the ASA-II category. Whereas in the Placebo group (group-B), $34(68 \%)$ were in ASA-I and $16(32 \%)$ in the ASA-II category (Table-I). The 
main surgical procedure was laparoscopic cholecystectomy $43 \%$ followed by septoplasty $28 \%$ Table-II shows the detail of other procedures.

\begin{tabular}{|c|c|c|}
\hline Description & $\begin{array}{l}\text { Group A (Dexme- } \\
\text { detomidine) n (\%) }\end{array}$ & $\begin{array}{c}\text { Group B } \\
\text { (Placebo) n (\%) }\end{array}$ \\
\hline Age in years & $35.24 \pm 11.49$ & $38.90 \pm 11.87$ \\
\hline \multicolumn{3}{|l|}{ Gender } \\
\hline Males & $26(52)$ & $29(58)$ \\
\hline Females & $24(48)$ & $21(42)$ \\
\hline \multicolumn{3}{|l|}{ ASA Status } \\
\hline ASA-I & $37(74)$ & $34(68)$ \\
\hline ASA-II & $13(26)$ & $16(32)$ \\
\hline
\end{tabular}

Table-II: Surgical procedures in which study was based.

\begin{tabular}{l|c|c} 
Surgical Procedure & $\begin{array}{c}\text { Group A } \\
\text { (Dexmedeto- } \\
\text { midine) } \mathbf{n}(\%)\end{array}$ & $\begin{array}{c}\text { Group B } \\
\text { (Placebo) n(\%) }\end{array}$ \\
\hline $\begin{array}{l}\text { Laproscopic } \\
\text { Cholecystectomy }\end{array}$ & $13(26)$ & $30(60)$ \\
\hline Thyroidectomy & $8(16)$ & $3(6)$ \\
\hline Mesh repair of hernia & $1(02)$ & $3(6)$ \\
\hline $\begin{array}{l}\text { Open reduction internal } \\
\text { fixation of Radius }\end{array}$ & $9(18)$ & $5(10)$ \\
\hline Septoplasty & $19(38)$ & $09(18)$ \\
\hline
\end{tabular}

The comparison of the change in the heart rate was done between the study and placebo group at baseline, 5 minutes, 10 minutes after drug administration and during direct laryngoscopy \& intubation (DLI). After that, the effect analysis was continued at, 1, 3, 5 and 10 minutes post DLI. The change in the heart rate of all cases is shown in Figure-1.

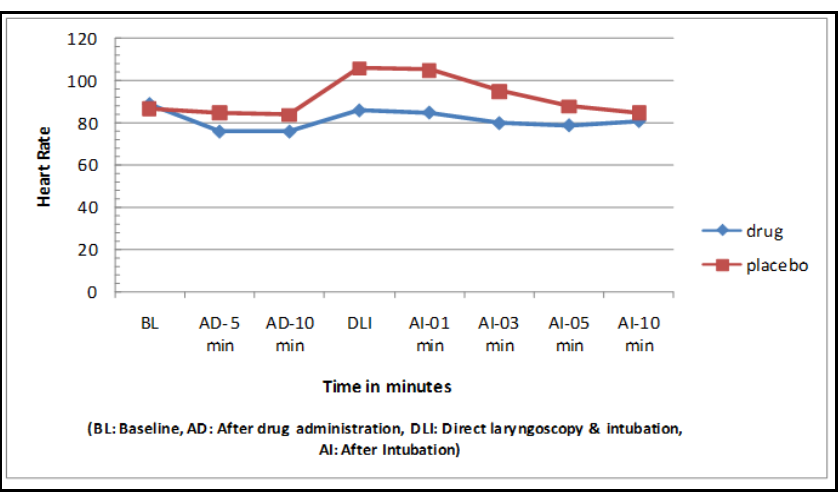

Figure-1: Changes in heart rate of all patients at different time intervals of two groups.

The changes were found statistically significant ( $p$-value $<0.05)$. The changes in the different age groups were also found significant, particularly during DLI and immediately after. Similarly, the comparison of the change in the systolic blood pressure was made between the study and placebo group at baseline, 5 minutes, 10 minutes after drug administration and during direct laryngo-scopy \& intubation. The comparison was continued for 1, 3, 5 and 10 minutes after DLI. The change in the systolic blood pressure of all cases is shown in Figure-2. The changes were found statistically significant ( $p$-value $<0.05)$. The changes of systolic blood pressure, in different age group were also found significant, parti-cularly during DLI and immediately after.

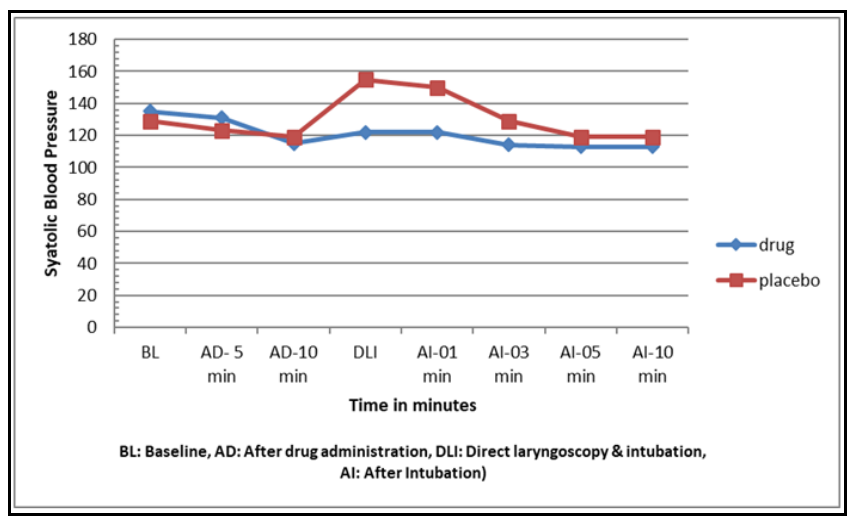

Figure-2: Changes in systolic blood pressure of all patients at different time intervals of two groups.

\section{DISCUSSION}

Laryngoscopy and endotracheal intubation are essential in airway management to administer general anaesthesia. This procedure of laryngoscopy and intubation can lead to a variable and sometimes significant hemodynamic response. ${ }^{9}$ This adrenergic response may be associated with severe hypertension, tachycardia which in turn may cause cardiac arrhythmias, myocardial ischemia and left ventricular dysfunction. ${ }^{10}$ Due to this hemodynamic stress response blood pressure and heart rate changes are seen in 15 seconds after laryngoscopy and becomes maximal after 30-45 seconds. These changes are mostly transient and well tolerated by healthy individuals. In patients with hypertension, coronary artery diseases and cerebrovascular diseases these changes may be associated with very serious consequences. ${ }^{11}$ Many drugs have been tried to reduce this stress response during L\&I. Various pharmacological agents like nitroglycerine, $\beta$ blocker, and opioids are used to provide hemodynamic stability during Laryngoscopy and intubation. ${ }^{12}$ Dexmedetomidine, the drug under study, is a relatively new highly selective a-2 agonist and a promising drug to provide hemodynamic stabilizing effects during L\&I. ${ }^{13}$ Due to a decrease in serum norepinephrine concentration, it causes a dose-dependent decrease in arterial blood pressure and heart rate, associated with Laryngoscopy 
and intubation. Its a2:a1 binding selectivity is very high, eight times more than clonidine. The optimal dose suggested to take care of hemodynamic stress response is $1 \mu \mathrm{g} / \mathrm{kg}$, with lesser doses not being effective. ${ }^{14}$ In the present study also this amount was used. The analgesic-sparing effect observed after a preoperative or an intraoperative administration of dexmedetomidine usually lasts up to 24 hands it is of paramount advantage where high anaesthetic concentration is either undesirable or not tolerated. . $^{15,16}$

In the study, 55 were male and 45 female patients in both groups $(n=100)$. The age range in group- $A$ (drug group) was 18-60 years and in group B (Placebo group) was 19-60 years and the difference of both groups was not significant. As well as gender distribution is concerned, there were more male patients in both groups and the same male predominance is also found in two Indian studies (Shah et al, and Sale et $a l,) .8,17$ The patients physical status as per the American Society of anaesthesiologists (ASA) physical status is concerned was comparable in both groups. The majority of the patients in both groups were in ASA-I physical status and this difference between ASA-I and ASAII was statistically insignificant. A similar result was found in other observations of different parts of India studies (Shah et al, , Sale et al, and Harharan et al,). In those comparative and placebo control studies also ASA-I and ASA-II, comparable, statistically insignificant status was selected. 8,17,18 Majority of the patients in the present study were undergoing cholecystectomy followed by a septoplasty. These surgical procedures were not affected modifier as ASA physical status was adhered to and the effect was to be analysed at intubation and laryngoscopy. Similar variable surgical procedures were adopted in an American and Indian study (Kakkar et al, and Hurwitz et al,). ${ }^{19,20}$

In the present study, at baseline, the mean heart rate variations were identified in both groups. Five and 10 min after administration of the drug in the study group there was a decrease in heart rate as compared to placebo and it was significant $(p<0.05)$. Then at the crunch moment of direct laryngoscopy and cut off point of $10 \mathrm{~min}$ after DLI the drug group maintained heart rate very well as compared to the placebo group. It was statistically highly significant. At the time of DLI the mean heart rate in the study group was $85.60 \pm$ $11.4 /$ min (less than mean basal value) as compared to the placebo group $106.30 \pm 13.04 / \mathrm{min}(22 \%$ above mean basal value). The same was observed by Shah et al, in their study. ${ }^{8}$ Ozair et al, ${ }^{21}$ while comparing dex- medetomidine with other drugs found a similar effect of the drug in decreasing the heart rate induced by the hemodynamic stress response. The Systolic Blood Pressure variation was also analysed in the present study. Previously in the study by Kunisawa et al, ${ }^{22}$ its was found that in the dexmedetomidine group systolic blood pressure was found lower at all times compared to baseline values and the same was found in the present study. At the time of direct laryngoscopy, till cut off point of $10 \mathrm{~min}$ after DLI, the drug group maintained systolic blood pressure very well as compared to the placebo group. It was statistically highly significant at the time of DLI, one minute and 3 minutes after DLI. It was observed by Ramshi et al, ${ }^{23}$ in their study. The systolic blood pressure changes similar to heart rate changes showed hemodynamic stabilizing effects. It is said that dexmedetomidine not only suppresses hemodynamic stress response by maintaining/decreasing heart rate and blood pressure but it also has perioperative anaesthetic sparing and post-operative analgesic sparing effects. ${ }^{24,25}$

\section{CONCLUSION}

Dexmedetomidine showed statistically significant stabilizing effects on the expected changes due to hemodynamic stress response of laryngoscopy and intubation. All patients in the study group responded very well to the stress induced by endotracheal intubation and the drug provided a stable hemodynamic state.

\section{Conflict of Interest: None.}

\section{Disclaimer}

The article is based on an approved dissertation for FCPS-II (Anesthesiology) by the CPSP.

\section{Authors' Contribution}

ARJ: Analysis, interpretation of data, drafting as PI, BY: Drug Acquisition, critical review, MS: Design of work, critical analysis, RASK: Supervisor, design of work, important intellectual input and final approval, SHAS: Concept, design, critical review, MZA: Co-PI, Analysis drafting of work.

\section{REFERENCES}

1. Hamaya $Y$, Dohi S. Differences in cardiovascular response to airway stimulation at different sites and blockade of the responses by lidocaine. Anesthesiol 2000; 93(1): 95-103.

2. Gotiwale K, Lele. Stress response to laryngoscopy and ease of intubation: comparison between macintosh and (levering) mccoys type laryngoscope. Int J Res Med Sci 2016; 4(8): 3141-3145.

3. Agarwal M, Malliwal A. Effect of dexmedetomidine on hemodynamic responses during tracheal extubation. Indian J Clin Anaesth, 2019; 6(1): 23-29.

4. Naz S, Ozair E. dexmedetomidine in current anaesthesia practice. J Clin Diagn Res 2014; 8(10): 1-4.

5. Zhou C. Effect of dexmedetomidine on postoperative cognitive dysfunction in elderly patients after general anaesthesia: A metaanalysis. J Int Med Res 2016; 44(6): 1182-1190. 
6. Canpolat DG, Yildirim MD, Kutuk N, Dogruel F, Ocak H, Aksu $\mathrm{R}$, et al. Comparison of ketamine-propofol and ketamine-dexmedetomidine combinations in children for sedation during tooth extraction. J Pak Med Assoc 2017; 67(5): 693-697.

7. Sulhyan SR, Vagarali AT, Patil SS, Dixit MD. A comparative clinical study of dexmedetomidine versus placebo to attenuate hemodynamic response to endotracheal intubation in patients undergoing off-pump coronary artery bypass grafting. J Sci Soc 2014; 41(3): 151-155.

8. Shah K, Bhut C, Gaukr N. Clinical evaluation of dexmedetomidine on hemodynamic stress response during laryngoscopy and intubation: A Randomized double-blind parallel-group placebocontrolled study. Ind J Clin Anaesth 2019; 6(1): 11-18.

9. Levitan RM, Heitz JW, Sweeney M, Cooper RM. The complexities of tracheal intubation with direct laryngoscopy and alternative intubation devices. Ann Emerg Med 2011; 57(3): 240-247.

10. Keniya VM, Ladi S, Naphade R. Dexmedetomidine attenuates the sympathoadrenal response to tracheal intubation and reduces perioperative anaesthetic requirement. Indian J Anesthesiol 2011; 55(4): 352-357.

11. Kwak HJ, Min SK, Yoo JY, Park KH, Kim JY. The median effective dose of dexmedetomidine for laryngeal mask airway insertion with propofol $2.0 \mathrm{mg} / \mathrm{kg}$. Acta Anaesthesiol Scand 2014; 58(7): 815-819.

12. Sulaiman S, Karthekeyan RB, Vakamudi M, Sundar AS, Ravullapalli H, Gandham R. The effects of dexmedetomidine on attenuation of stress response to endotracheal intubation in patients undergoing elective off-pump coronary artery bypass grafting. Ann Card Anaesth 2012; 15(1): 39-43.

13. Yazbek-Karam VG, Aouad MM. Perioperative uses of dexmedetomidine. Middle East J Anaesthesiol 2006; 18(6): 1043-1058.

14. Keniya VM, Ladi S. Dexmedetomidine attenuates the sympathoadrenal response to tracheal intubation and reduces perioperative anaesthetic requirement. Ind J Anaesth 2011; 55(4): 352-357.

15. Paranjpe JS. Dexmedetomidine: Expanding role in anaesthesia. Med J DY Patil Univ 2013; 6(1): 5-13.
16. Sarkar J, Anand T, Kamra SK. Hemodynamic response to endotracheal intubation using C-Trach assembly and direct laryngoscopy. Saudi J Anaesth 2015; 9(4): 343-347.

17. Sale HK, Shendage VJ. Lignocaine and dexmedetomidine in attenuation of pressor response to laryngoscopy and intubation: a prospective study. Int J Sci Stud 2015; 3(9): 155-160.

18. Hariharan S, Biju ML, Parukutty P. Efficacy of intravenous dexmedetomidine versus lidocaine in attenuation of stress response during intubation for laparoscopic procedures. Int J Biomed Res 2016; 7(3): 99-107.

19. Kakkar A, Tyagi A, Nabi N, Sethi AK, Verma UC. Comparison of clonidine and dexmedetomidine for attenuation of laryngoscopy and intubation response - a randomized controlled trial. J Clin Anesth 2016; 33(9): 283-288.

20. Hurwitz EE, Simon M, Vinta SR, Zehm CF, Shabot SM, Minhajuddin A, et al. Adding examples to the ASA-physical status classification improves correct assignments to patients. Anesthesiol 2017; 126(4): 614-622.

21. Ozair E, Ali QE. A comparative eval-uation of dexmedetomidine and fentanyl to attenuate hemody-namic response to laryngoscopy and intubation. Asian J Med Sci 2018; 9(1): 65-72.

22. Kunisawa T, Nagata O, Nagashima M, Mitamura S. Dexmedetomidine suppresses the decrease in blood pressure during anaesthetic induction and blunts the card-iovascular response to tracheal intubation. J Clin Anesth 2009; 21(3): 194-199.

23. Rashmi HD, Komala HK. Clinical evaluation of the effect of intravenous dexmedetomidine on the hemodynamic response to laryngoscopy and endotracheal intubation in patients undergoing thyroid surgeries. Anesth Essays Res 2016; 10(3): 483-487.

24. Keniya VM, Ladi S, Naphade R. Dexmedetomidine attenuates the sympathoadrenal response to tracheal intubation and reduces perioperative anaesthetic requirement. Indian J Anaesth 2011; 55(4): 352-357.

25. Tang C, Xia Z. Dexmedetomidine in perioperative acute pain management: a non-opioid adjuvant analgesic. J Pain Res 2017; 10(8): 1899-1904. 